\title{
Experience on Early Urethral Catheter Removal Following Radical Prostatectomy
}

\author{
Hyeong Dong Yuk ${ }^{1}$, Gyoohwan Jung', Min Young Yoon ${ }^{1}$, Juhyun Park², \\ Sung Yong $\mathrm{Cho}^{2}$, Hwancheol Son ${ }^{2}$, Hyeon Jeong ${ }^{2}$ \\ ${ }^{1}$ Department of Urology, Seoul National University Hospital, \\ ${ }^{2}$ Department of Urology, SMG-SNU Boramae Medical Center, Seoul, Korea
}

Purpose: To assess outcomes from patients who underwent radical prostatectomy and had their indwelling urinary catheter removed on postoperative day (POD) 4 or 7 .

Materials and Methods: The medical records of 107 consecutive patients receiving radical prostatectomy (RP), were retrospectively reviewed. Patients were categorized into two groups according to length of catheterization. Group $1(n=40)$ had the urethral catheter removed on postoperative day (POD) 4 , and group $2(n=67)$ had the catheter removed on POD7. Group 1 had urethral catheter removal following no leakage on intraoperative leak testing and POD4 cystography, whilst group 2 exhibited leakage at POD4 and instead had routine POD7 urethral catheter removal if there was evidence of no leakage of POD7 cystography. Incontinence was checked according to the use of protective pad.

Results: The mean age of the study population was 67.0 years. acute urinary retension (AUR) following catheter removal occurred in 6 of the cohort (5.6\%); 3 patients $(7.5 \%)$ from group 1 and $3(4.5 \%)$ from group $2(\mathrm{p}=0.669)$. The overall continence rate was $39.3 \%, 68.2 \%, 80.4 \%$, and $91.6 \%$ at $1,3,6$, and 12 months respectively. Importantly, the incontinence recovery pace of group 1 was notably higher than that of group $2(p=0.001)$. Neither group exhibited bladder neck contracture. Intraoperative factors influencing the decision to remove catheter at POD4 following RP, are bladder neck reconstruction $(\mathrm{OR}=3.792, \mathrm{p}=0.010)$ and nerve sparing $(\mathrm{OR}=6.646, \mathrm{p}=0.008)$.

Conclusions: Selective early urethral catheter removal may shorten the length of incontinence recovery, without increasing the risk of AUR and bladder neck contracture. (Korean J Urol Oncol 2016;14:76-81)

Key Words: Radical prostatectomy, Prostate cancer, Urethral catheter, Incontinence

\section{INTRODUCTION}

Patel and Lepor at el observed a postoperative day (POD) 4 urethral catheter removal group, in which $76.8 \%$ exhibited no leakage on cystography following retropubic radical prostatectomy (RRP), however $15.2 \%$ experienced acute urinary retension (AUR) following urethral catheter removal. Following

Received March 28, 2016, Revised May 17, 2016 (1st), June 10, 2016 (2nd), July 4, 2016 (3rd), Accepted July 8, 2016 Corresponding Author: Hyeon Jeong, Department of Urology, SMG-SNU Boramae Medical Center, 20, Boramae-ro 5-gil, Dongjak-gu, Seoul 07061, Korea. Tel: 82-2-870-2177, Fax: 82-2-870-3863, E-mail: drjh@brm.co.kr these observations of an elevated AUR risk, Patel and Lepor et al. recommend POD7 urethral catheter as opposed to removal POD4. ${ }^{1}$ In the previous decade, radical prostatectomy (RP) techniques have been developed by many urologists, ${ }^{2-5}$ allowing postoperative management to changed. Recently, several investigations have reported that early POD3-4 urethral catheter removal following RP is safe and feasible. ${ }^{6-9}$ In this study, we confirm the feasibility of early urethral catheter removal, and provide clinical indications to aid in the decision of early urethral catheter removal, via intraoperative leak testing and POD4 cystography. 


\section{MATERIALS AND METHODS}

Between april 4, 2008 and august 14, 2014, 107 men underwent retropubic radical prostatectomy $(n=26)$, robotic assisted laparoscopic prostatectomy (RALP, $\mathrm{n}=44$ ) or laparoscopic radical prostatectomy (LRP, $\mathrm{n}=37$ ) from a single surgeon. The board approved a retrospective chart review and analysis. RRP and RALP procedures were performed under general anesthesia, with vesicourethral anastomosis performed via six interrupted 2-0 vicryl (Ethicon) sutures tied in RRP and LRP, or with continuous 3-0 v-loc sutures in RALP. Bladder neck reconstruction was performed in all cases. Nerve sparing and pelvic lymph node dissection was performed with consideration of preoperative factors. A 16-Fr urethral catheter was inserted as routine in all cases. Additionally, cystography was performed routinely on either POD4 (group 1), or POD7 (group 2). Patients had urethral catheters removed following evidence of no leakage on cystography. After removal of the urethral catheter, incontinence was rated according to the number of protective pads used in 24hrs at each of 1, 3, 6, 9, 12 and 24 months. We used the Kaplan-Meier method and student $t$ test for continence recovery rate analysis and multivariate analysis for derivation of meaningful factors.

\section{RESULTS}

A total of 107 patients were divided into two groups. Group $1(n=40)$ had POD4 urethral catheter removal following no leakage on intraoperative leak testing and POD4 cystosgraphy, whilst group $2(\mathrm{n}=67)$ exhibited leakage at POD4 and instead had routine POD7 urethral catheter removal if there was evidence of no leakage of POD7 cystography. Overall clinical stage was $\mathrm{T} 1$ in 67 cases and T2 in 40, average prostate volume was $32.0 \pm 1.1 \mathrm{~g}$, median PSA was $10.4 \pm 32.2$. Patient characteristics are shown Table 1. Patient age, BMI, PSAD, operative time, mean blood loss, preoperative Gleason score, serum PSA and clinical stage were compared between groups 1 and 2 (Table 1), with no meaningful differences. All patients received complete bladder neck reconstruction. Nerve sparing and pelvic lymph node dissection was performed with consideration of preoperative factors. After performing a $250 \mathrm{cc}$ intraoperative leak test, and postoperative cystography, urethral catheter removal exhibited no leakage in cystography. All patients from group 1 exhibited no leakage upon cystography, however, two patients from group 2 exhibited leakage, with the urethral catheter left indwelling in these cases. The median follow up of patients is a 2 years. Incidence of AUR was 5.6\% (6 patients); 3 patients (7.5\%) from group 1, and $3(4.5 \%)$ from group 2.

Table 1. Baseline characteristics

\begin{tabular}{|c|c|c|c|c|}
\hline Parameter & Overall $(n=107)$ & $\begin{array}{l}\text { Group } 1(\mathrm{n}=40 \text {, catheter } \\
\text { removal on POD4) }\end{array}$ & $\begin{array}{l}\text { Group } 2(\mathrm{n}=67 \text {, catheter } \\
\text { removal on POD7) }\end{array}$ & p-value \\
\hline Mean age (years) & $67.0 \pm 5.9$ & $66.5 \pm 5.9$ & $68.0 \pm 6.0$ & 0.434 \\
\hline Median BMI & $24.0 \pm 5.8$ & $22.9 \pm 2.5$ & $24.6 \pm 7.1$ & 0.455 \\
\hline Median PSA (ng/ml) & $10.4 \pm 32.2$ & $11.3 \pm 12.3$ & $9.5 \pm 39.3$ & 0.465 \\
\hline PSAD & $0.31 \pm 1.08$ & $0.34 \pm 0.40$ & $0.30 \pm 1.33$ & 0.465 \\
\hline prostate volume (ml) & $32.0 \pm 1.1$ & $31.0 \pm 8.5$ & $34.0 \pm 12.8$ & 0.741 \\
\hline Operative time (min) & $210.0 \pm 76.6$ & $207.5 \pm 52.8$ & $220.0 \pm 88.3$ & 0.065 \\
\hline Mean Blood loss (ml) & $400.0 \pm 501.3$ & $300.0 \pm 229.1$ & $425.0 \pm 592.5$ & 0.585 \\
\hline Clinical Stage & & & & 0.202 \\
\hline $\mathrm{T} 1 \mathrm{c}$ & $67(62.6 \%)$ & $28(70.0 \%)$ & $39(58.2 \%)$ & \\
\hline $\mathrm{T} 2$ & $40(37.4 \%)$ & $12(30.0 \%)$ & $28(41.8 \%)$ & \\
\hline Pathological Gleason score & & & & 0.862 \\
\hline$<7$ & $32(29.9 \%)$ & $14(35.0 \%)$ & $18(26.9 \%)$ & \\
\hline$=7$ & $55(51.4 \%)$ & $22(55.0 \%)$ & $33(49.3 \%)$ & \\
\hline$>7$ & $20(18.7 \%)$ & $4(10.0 \%)$ & $16(23.9 \%)$ & \\
\hline LN positive & $20(28 \%)$ & $14(35 \%)$ & $16(23.9 \%)$ & 0.267 \\
\hline Surgical margin positive & $45(42.1 \%)$ & $13(32.5 \%)$ & $32(47.8 \%)$ & 0.157 \\
\hline
\end{tabular}

POD: Postoperative day, BMI: Body mass index, PSA: Prostate-specific antigen, PSAD: Prostate-specific antigen density, LN: Lymph node. 
Table 2. Urinary continence recovery rate according to the groups

\begin{tabular}{lcccc}
\hline Continence & Overall $(\mathrm{n}=107)$ & $\begin{array}{c}\text { Group1 }(\mathrm{n}=40, \text { catheter } \\
\text { removal on POD4) }\end{array}$ & $\begin{array}{c}\text { Group2 (n=67, catheter } \\
\text { removal on POD7) }\end{array}$ & p-value \\
\hline At 1 mo & $42(39.3 \%)$ & $21(52.5 \%)$ & $21(31.3 \%)$ & 0.041 \\
At 3 mo & $73(68.2 \%)$ & $33(82.5 \%)$ & $40(59.7 \%)$ & 0.018 \\
At 6 mo & $86(80.4 \%)$ & $37(92.5 \%)$ & $49(73.1 \%)$ & 0.022 \\
At 9 mo & $91(85.0 \%)$ & $39(97.5 \%)$ & $52(77.6 \%)$ & 0.005 \\
At 12 mo & $94(87.9 \%)$ & $39(97.5 \%)$ & $55(82.1 \%)$ & 0.029 \\
At 24 mo & $98(91.6 \%)$ & $40(100 \%)$ & $58(86.6 \%)$ & 0.025 \\
\hline
\end{tabular}

POD: Postoperative day.

Table 3. Urinary continence recovery rate according to surgery types

\begin{tabular}{ccccc}
\hline Continence & RRP $(\mathrm{n}=26)$ & LRP $(\mathrm{n}=37)$ & $\operatorname{RALP}(\mathrm{n}=44)$ & $\mathrm{p}$-value \\
\hline At $1 \mathrm{mo}$ & $11(42.3 \%)$ & $11(29.7 \%)$ & $20(45.5 \%)$ & 0.330 \\
At $3 \mathrm{mo}$ & $19(73.1 \%)$ & $20(54.1 \%)$ & $34(77.3 \%)$ & 0.068 \\
At $6 \mathrm{mo}$ & $22(84.6 \%)$ & $24(64.9 \%)$ & $40(90.9 \%)$ & 0.011 \\
At $9 \mathrm{mo}$ & $23(88.5 \%)$ & $27(73.0 \%)$ & $41(93.2 \%)$ & 0.034 \\
At $12 \mathrm{mo}$ & $24(92.3 \%)$ & $28(75.7 \%)$ & $42(95.5 \%)$ & 0.018 \\
At $24 \mathrm{mo}$ & $24(92.3 \%)$ & $30(81.1 \%)$ & $44(100 \%)$ & 0.009 \\
\hline
\end{tabular}

POD: Postoperative day, RRP: Retropubic radical prostatectomy, RALP: Robotic assisted laparoscopic prostatectomy, LRP: Laparoscopic radical prostatectomy.

Neither group exhibited bladder neck contracture. AUR and bladder neck contracture risk rate showed no meaningful differences between groups. The overall continence rate was measured at $39.3 \%, 68.2 \%, 80.4 \%, 85.0 \%, 87.9 \%$ and $91.6 \%$ at 1 , $3,6,9,12$ and 24 months respectively. Group 1 continence rates were $52.5 \%, 82.5 \%, 92.5 \%, 97.5 \%, 97.5 \%$ and $100 \%$ across the same time points, with group 2 continence rates at $31.3 \%, 59.7 \%, 73.1 \%, 77.6 \%, 82.1 \%$ and $86.6 \%$ (Table 2). In comparison continence rate according to the type of surgery, The RRP continence rate was measured at $42.3 \%, 73.1 \%$, $84.6 \%, 88.5 \%, 92.3 \%$ and $92.3 \%$ at $1,3,6,9,12$ and 24 months respectively. LRP continence rates were $29.7 \%, 54.1 \%$, $64.9 \%, 73.0 \%, 75.7 \%$ and $81.1 \%$, RALP continence rates at $45.5 \%, 77.3 \%, 90.9 \%, 93.2 \%, 95.5 \%$ and $100 \%$ (Table 3). The incontinence recovery rate was substantially greater for group 1 than that of group 2 (Fig. 1). Additionally, significant differences between the two groups were observed in bladder neck reconstruction rate and the nerve sparing rate; in both cases. group 1 exhibited higher rates than those measured in group 2 Intraoperative factors influencing the decision to remove a catheter at POD4 following RP, in multivariate analysis, are

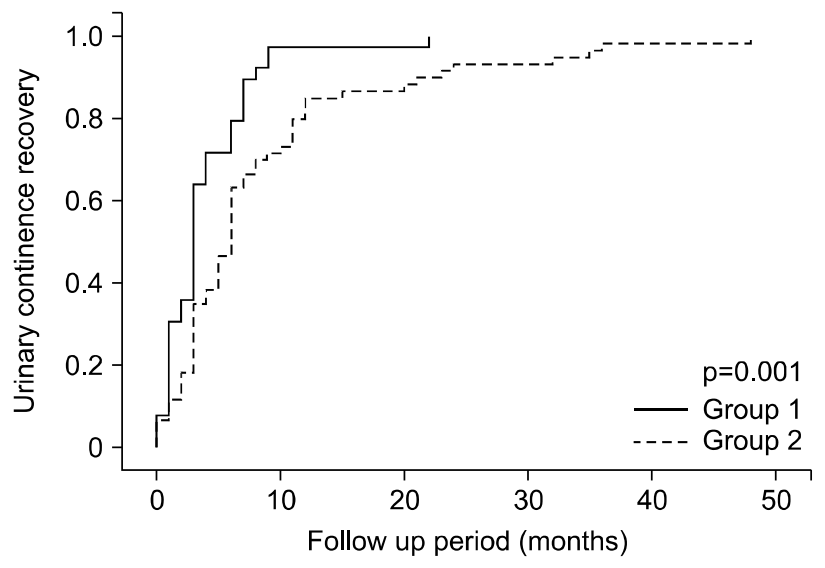

Fig. 1. Urinary continence recovery rate according to the groups. The incontinence recovery rate was substantially greater for group 1 than that of group 2. Group 1: catheter removal on POD4, Group 2: catheter removal on POD7.

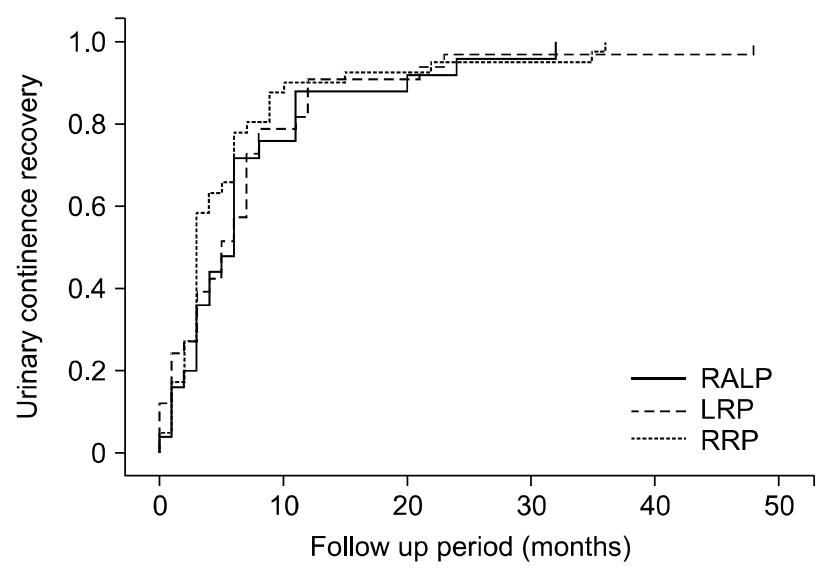

Fig. 2. The incontinence recovery rate was differnt depending on the surgery types. RALP showed the highest recovery rate. RRP was higher in the second and LRP showed the lowest recovery rate. RRP: Retropubic radical prostatectomy, RALP: Robotic assisted laparoscopic prostatectomy, LRP: Laparoscopic radical prostatectomy. 
bladder neck reconstruction $(\mathrm{OR}=3.792, \mathrm{p}=0.010)$ and nerve sparing $(\mathrm{OR}=6.646, \mathrm{p}=0.008)$. Further, the postoperative factor is the duration of urethral catheter indwelling $(\mathrm{HR}=3.792$, $\mathrm{p}=0.010$ ), as determined). The incontinence recovery rate was differnt depending on the surgery types. RALP showed the highest recovery rate. RRP was higher in the second and LRP showed the lowest recovery rate (Fig. 2).

\section{DISCUSSION}

A number of studies have examined early urethral catheter removal, with some high volume centers even enforcing early urethral catheter removal. However, anastomotic stricture, urinary incontinence, bladder contracture, urinoma and pelvic abscesses remain risks. For these reasons, many urologists have not readily implemented an early urethral catheter removal protocol. ${ }^{6,7}$ However, many patients exhibit no leakage on cystography taken earlier than POD7 in the recovery phase. ${ }^{6-8}$ In a recent survey, early urethral catheter removal has been assessed as having a similar, or even lower rate, of complications following surgery. ${ }^{9-12}$ Coelho et al. have, at their centers, enforced Foley catheter removal at POD5-POD7, with notably lower chances of urinary retention $(<1 \%) .{ }^{9}$ Tiguert et al. observed POD4 and POD7 groups as a means of comparing continence rates at 3,9 and 12 months, with all rates higher in the POD4 group than in the POD7 group, and bladder neck contracture rates of $4 \%$ and $6 \%$, respectively. Thus, POD 4 groups have exhibited fewer incontinence issues and bladder neck contractures than the POD7 group. ${ }^{10}$ In a study performed by Souto et al., one group of patients underwent removal of the urethral catheter on POD4 or 5 if no leakage on cystography was observed, with another group having the urethral catheter removed 14 days after surgery, with no cystography at all. When comparing the urinary continence rates of this study there were no meaningful differences. Additionally, other the rate of other complications also exhibited no meaningful difference. On the other hand, bladder neck contracture and urethral stenosis may be at least partially attributable to a longer catheterization period. ${ }^{11}$ Lepor et al. compare a POD7 removal group to a POD14 group, with POD7 urethral catheter removal not exhibiting an increase in the risk of complications or compromising overall urinary continence. ${ }^{1}$ Further, Choichiro et al. compare POD3 and POD5 removal groups, with no significant difference in terms of continence rate between POD3 and
POD5. ${ }^{12}$ Our results of early urethral catheter removal show a meaningful correlation between rate of urinary incontinence recovery following the operation, and time to pad-free, with early urethral catheter removal. Consistent with previous research, AUR and bladder neck contracture were not observed to be remarkably different.

Bladder neck reconstruction and nerve saving was also correlated with urinary incontinence recovery. Bladder neck reconstruction has more influence on proper bladder neck shape, urethral blood supply and pelvic floor reinforcement, ${ }^{13}$ with nerve saving also able to preserve the perivesical nerve, urethral, and prostate surrounding nerve. ${ }^{14}$ We should note that choice of targets is one of the most important clinical points in early urethral catheter removal. Selection through intraoperative leakage test and cystography is necessary. We used leakage test and cystography as screening criteria. The leakage test involves intraoperative saline instillation to detect urine leakage. However, there remains no clear criterion for choice of instilled volume. The range of volume varied from $120 \mathrm{ml}$ to $250 \mathrm{ml} .{ }^{15-17}$ The bladder should have constant low pressure, not reaching more than 6-10 $\mathrm{cm} \mathrm{H}_{2} \mathrm{O}(4.41-7.35 \mathrm{mmHg})$ above baseline at the end of filling (end-filling pressure), with no involuntary contractions and normal first sensation ranging between 100 and $250 \mathrm{ml}^{18}$ Median intrabladder pressure was $1.5 \mathrm{mmHg}$ at $50 \mathrm{ml}, 2.5 \mathrm{mmHg}$ at $100 \mathrm{ml}, 5.5 \mathrm{mmHg}$ at $150 \mathrm{ml}$, and up to $11 \mathrm{mmHg}$ at $300 \mathrm{ml} .{ }^{19}$ Most patients with prostatectomy incontinence demonstrate stress incontinence at a bladder volume of approximately $150 \mathrm{ml} .^{20}$ Abdominal leak point of prostatectomy incontinence (voiding leak point pressure) has been observed at a filling volume of $200 \mathrm{ml} .^{21}$ Faerber et al. serial Valsalva leak point pressure testing was performed at 50cc volume increments up to $400 \mathrm{cc}$ bladder volume. Determination of leak point pressure at bladder volumes of 250 to $300 \mathrm{cc}$ using the Valsalva maneuver appears to be the most beneficial application of this test. Consequently, following bladder neck reconstruction and vesicourethral anastomosis, we performed a leakage test to confirm a watertight anastomosis. After filling the urinary bladder with $250 \mathrm{ml}$ saline during surgery, pressure was applied to resemble a situation such as high intravesical pressure. ${ }^{22}$ If patients exhibited a watertight vesicourethral anastomosis, they were checked at POD4 with cystography, and had urethral catheter removed with no leakage on cystography.

In out study, urinary incontinence recovery rate was different depending on the surgery types. RALP showed the highest re- 
covery rate. RALP use the free articulation instruments and three dimensional enlared view. these points had more influence on urethrovesical anastomosis, bladder neck reconstruction, urethral and pelvic floor blood supply. ${ }^{23}$ Di prerro et al. reported RALP was higer postoperative recovery rate than RRP. ${ }^{24}$ Tewari et al. there was a differrence in that recovey period. RALP was 44 days and RRP was 160 days. ${ }^{25}$ Hakimi AA et al. observed RALP group and LRP group as a means of comparing faster return of the continence was at 3, 6 and 12 months, with all rate faster in the RALP group than in the LRP group. $^{26}$

The major limitation of this study was its retrospective design, long periods as 7 years, and three different procedures in addition to a short term follow up duration and small number of patients. Even with these limitations, urinary continence continues to worsen, but rarely, and therefore we assume future results will be consistent with what we have observed. If cystography performed at the regular time and urethral catheter removal were divided into different groups, It could be a more meaningful conclusions.

\section{CONCLUSION}

Selective early urethral catheter removal is feasible and not increasing the risk of AUR and bladder neck contracture, If we select a target to take into account several factors, selective early urethral catheter removal can be another measure to minimize complication and patient's discomfort and hospitalization.

\section{REFERENCES}

1. Lepor H, Nieder AM, Fraiman MC. Early removal of urinary catheter after radical retropubic prostatectomy is both feasible and desirable. Urology 200;58:425

2. Walsh PC, Partin AW. Anatomic radical retropubic prostatectomy. In: Wein AJ, Kavoussi LR, Novick AC et al. (eds). Campbell-Walsh Urology, 9th edn, Vol. 3, Chapter 97. WB Saunders, Philadelphia, PA, 2007;2956-78

3. Lowe BA. Comparison of bladder neck preservation to bladder neck resection in maintaining postprostatectomy urinary continence. Urology 1996;48:889-93

4. Poon M, Ruckle H, Bamshad BR, et al. Radical retropubic prostatectomy: Bladder neck preservation versus reconstruction. J Urol 2000;163:194-8

5. Shelfo SW, Obek C, Soloway MS. Update on bladder neck preservation during radical retropubic prostatectomy: Impact on pathologic outcome, anastomotic strictures, and continence. Urology 1998;51:73-8

6. Dalton DP, Schaeffer AJ, Garnett J E, et al. Radiographic assessment of the vesicourethral anastomosis directing early decatheterization following nerve-sparing radical retropubic prostatectomy. J Urol 1989;141:79

7. Leibovitch I, Rowland RG, Little JS Jr, et al. Cystography after radical retropubic prostatectomy: clinical implications of abnormal findings. Urology 1995;46:78

8. Little JS Jr, Bihrle R, Foster RS. Early urethral catheter removal following radical prostatectomy: a pilot study. Urology 1995;46:429

9. Tiguert R, Rigaud J, Fradet Y. Safety and outcome of early catheter removal after radical retropubic prostatectomy. Urology 2004;63:513-7

10. Coelho RF, Chauhan S, Orvieto MA, et al. Influence of modi fied posterior reconstruction of the rhabdosphincter on early recovery of continence and anastomotic leakage rates after robot-assisted radical prostatectomy. Eur Urol 2011;59:72-80

11. Souto CA, Teloken C, Souto JC, et al. Experience with early catheter removal after radical retropubic prostatectomy $\mathrm{J}$ Urol 2000;163:865-6

12. Choichiro O, Jun H, Yoshihiro N. retropubic prostatectomy with running vesicourethral International Journal of Urology 2009; 16:487-92

13. Tan G, Srivastava A, Grover S, Peters D, Dorsey Jr P, Scott A, et al. Optimizing vesicourethral anastomosis healing after robot-assisted laparoscopic radical prostatectomy: lessons learned from three techniques in 1900 patients. J Endourol 2010;24:1975e83

14. Hoshi A, et al. Total pelvic floor reconstruction during non-nerve-sparing laparoscopic radical prostatectomy: impact on early recovery of urinary continence. Int J Urol 2014;21: $1132-7$

15. Kojima Y, Takahashi N, Haga N, Nomiya M, YanagidaT, Ishibashi K, Aikawa K, Lee DI. Urinary incontinence after robot-assisted radical prostatectomy: pathophysiology and intraoperative Techniques to improve surgical outcome. Int $\mathbf{J}$ Urol 2013;20:1052-63

16. Freire MP, Choi WW, Lei Y, Carvas F, Hu JC. Overcoming the learning curve for robotic-assisted laparoscopic radical prostatectomy. Urol Clin North Am 2010;37:37e47

17. Guru KA, Seereiter PJ, Sfakianos JP, Hutson AD, Mohler JL. Is a cystogram necessary after robot-assisted radical prostatectomy? Urol Oncol 2007;25:465e7

18. Mahfouz W, Afraa TA, Campeau L. Normal urodynamic parameters in women Int Urogynecol J 2012;23:269-77

19. Malbrain ML, Deeren DH. Effect of bladder volume on measured intravesical pressure: a prospective cohort study Critical Care 2006, 10:R98 (doi:10.1186/cc4962)

20. Comiter CV, Sullivan M, Yalla SV. Correlation among maximal urethral closure pressure, retrograde leak point pressure, 
and abdominal leak point pressure in men with postprostatectomy incontinence. Urology 2003;62:75-8

21. Stephanie J. Kielb, J. Quentin Clemens. Comprehensive urodynamics evaluation of 146 men with incontinence after radical prostatectomy 2005;66:392-6

22. Faerber GJ, Vashi AR. Variations in Valsalva leak point pressure with increasing vesical volume. J Urol 1998;159:1909

23. Son SJ, Lee SC, Jeong CW, Jeong SJ, Byun SS, Lee SE. Comparison of continence recovery between robot-assisted laparoscopic prostatectomy and open radical retropubic prostatectomy: a single surgeon experience. Korean J Urol 2013;54: 598-602

24. Di Pierro GB, Baumeister P, Stucki P, Beatrice J, Danuser
$\mathrm{H}$, Mattei A. A prospective trial comparing consecutive series of open retropubic and robot-assisted laparoscopic radical prostatectomy in a centre with a limited caseload. Eur Urol 2011;59:1-6

25. Tewari A, Srivasatava A, Menon M. Members of the VIP Team. A prospective comparison of radical retropubic and robot-assisted prostatectomy: experience in one institution. BJU Int 2003;92:205-10

26. Hakimi AA, Blitstein J, Feder M. Direct comparison of surgical and functional outcomes of robotic-assisted versus pure laparoscopic radical prostatectomy: single-surgeon experience. Urology 2009;73:119-23 